\title{
Microstructure Formation Mechanism During a Novel Semisolid Rheo-rolling Process of AZ91 Magnesium Alloy
}

\author{
Zhanyong ZHAO, Renguo GUAN ${ }^{\dagger}$, Xiang WANG and Chunming LIU \\ College of Materials and Metallurgy, Northeastern University, Shenyang 110189, China \\ [Manuscript received 16 December 2012, in revised form 28 March 2013] \\ (C) The Chinese Society for Metals and Springer-Verlag Berlin Heidelberg
}

\begin{abstract}
A novel semisolid rheo-rolling process of AZ91 alloy was proposed. The microstructure formation mechanism of AZ91 magnesium alloy during the process was studied. The results reveal that the eruptive nucleation and the heterogeneous nucleation exist. During the grain growth process, the grain breakage took place and transformed into fine spherical or rosette grains on the sloping plate gradually, the other grain growth style is direct globular growth. Due to the secondary crystallization of the remnant liquids in the roll gap, the microstructure of the strip becomes finer with the increment of the casting temperature from $650{ }^{\circ} \mathrm{C}$ to $690{ }^{\circ} \mathrm{C}$. But when the casting temperature reached $710^{\circ} \mathrm{C}$, a part of the liquid alloy transformed into the eutectic phases, and the primary grains ripened to form coarse dendrites. In the casting temperature range from $650{ }^{\circ} \mathrm{C}$ to $690{ }^{\circ} \mathrm{C}, \mathrm{AZ91}$ alloy strip with fine spherical or rosette grains was prepared by the proposed process.
\end{abstract}

KEY WORDS: Semisolid; Rolling; AZ91 alloy; Microstructure

\section{Introduction}

As structural materials, magnesium alloys have good performances, and the resource of $\mathrm{Mg}$ is very rich in the earth. Therefore, magnesium alloys have a good application tendency in recent years. However, the crystal lattice of magnesium is the hcp structure with few independent slip systems in the matrix, so the deformation ability of magnesium alloys is not high, and the production efficiency of magnesium alloy materials is usually very low ${ }^{[1-3]}$. Therefore, the research on the plastic forming of wrought magnesium alloys has become an important subject ${ }^{[4-6]}$. Because semisolid processing technique has the advantages of easy forming, good product microstructure and performances, it was widely studied in the world $^{[7-9]}$. Especially, semisolid forming improves the plasticity of magnesium alloys, and it is regard as a convenient processing technique of magnesium alloy. As a convenient slurry preparation technique, sloping plate process has been developed rapidly in recent

† Corresponding author. Prof., Ph.D.; Tel: +86 24 83681463; E-mail address: guanrg@smm.neu.edu.cn (Renguo GUAN)

DOI: $10.1007 / \mathrm{s} 40195-012-0261-7$ years. During this process, the alloy melt is cast onto a sloping plate, and under the actions of the cooling and melt flow, the semisolid slurry can be prepared ${ }^{[10,11]}$. Many researchers investigated this process. Motegi ${ }^{[12]}$ successfully manufactured semisolid billet in size of $50 \mathrm{~mm} \times 1000 \mathrm{~mm}$ of $\mathrm{Al}-\mathrm{Si}-\mathrm{Mg}$ alloy by using this method. Plato Kapranos et al. ${ }^{[13]}$ in the University of Sheffield, Grimmig et al. ${ }^{[14]}$ in RWTH Aachen and Salarfar et al. ${ }^{[15]}$ in the Tehran University have also carried out many research works on this technique. Haga et al. ${ }^{[16,17]}$ in the Osaka Institute of Technology has investigated the rheo-rolling process of aluminum alloys by combining the rollcasting mill and the sloping plate. However, semisolid rheo-rolling of magnesium alloy is a new technique that needs further study, and the problems of slurry adhesion on the plate surface and the liquid segregation commonly occurred in the semisolid rolling should be resolved. In this work, in order to deal with the above problems, a novel semisolid rheorolling process of AZ91 magnesium alloy has been developed by combining the vibrating sloping plate and the shape rolling mill, through the proposed process, the troubles of the slurry adhesion and the liquid seg- 


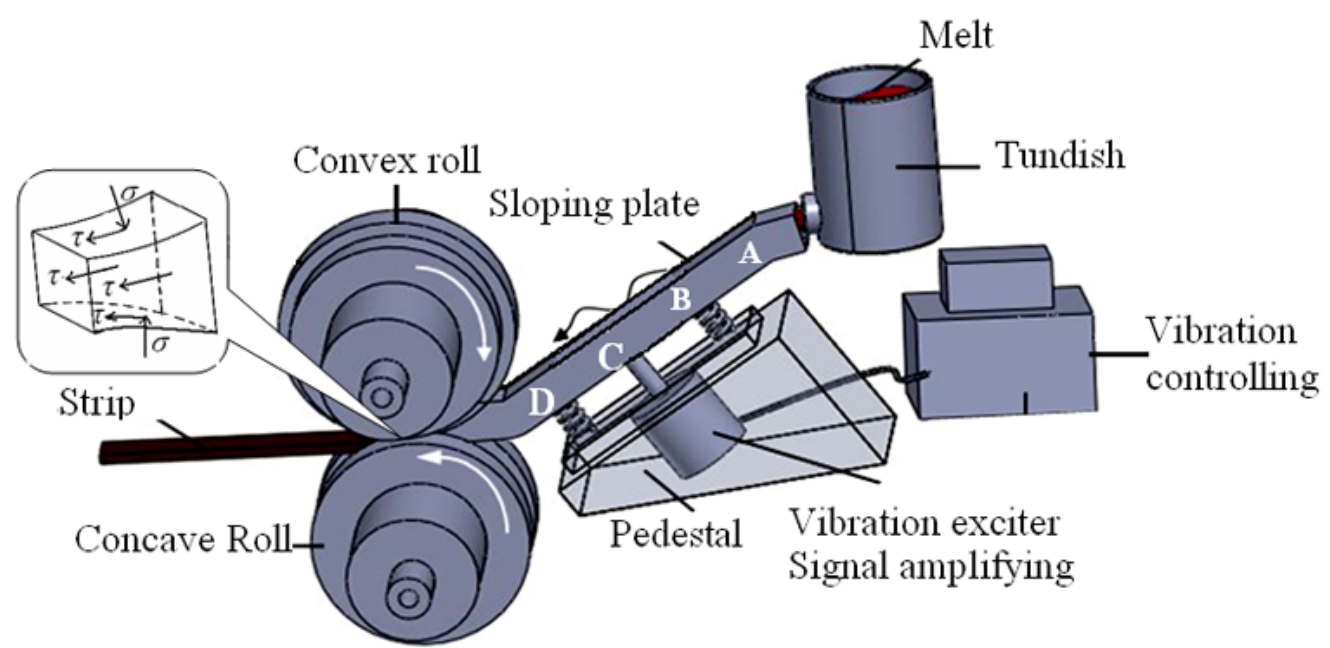

Fig. 1 Schematic diagram of the semisolid rheo-rolling and the force diagram of the slurry in rolling gap (A, B, $\mathrm{C}$ and $\mathrm{D}$ are $0 \mathrm{~mm}, 150 \mathrm{~mm}, 300 \mathrm{~mm}$ and $400 \mathrm{~mm}$ from the casting mouth, respectively)

regation were solved. Since the mechanical properties of the strip depend on the inner microstructure of the product, the microstructure formation mechanism during semisolid forming process has been study. Though the microstructure formation mechanism of Mg-3Sn-1Mn (wt.\%) magnesium alloy processed by the semisolid continuous shearing and rolling process was reported in Ref. [18], but the semisolid continuous shearing and rolling process is different from the semisolid rheo-rolling process. In Ref. [19], the fabrication of AZ31 alloy wire by continuous semisolid extrusion process was reported, the continuous semisolid extrusion process is different from the semisolid rheo-rolling process. The mechanism of the dendrite fracture of Mg-3Sn-1Mn (wt.\%) magnesium alloy during the semisolid rheo-rolling process was reported in Ref. [20]. In Ref. [21], it was mainly reported the solidification behaviors of A2017 alloy during cooling/stirring and rolling process. On the basis of previous studies, the microstructure formation mechanism of AZ91 magnesium alloy during the process and the effects of casting temperature on microstructure of the product are studied deeply ${ }^{[2,21]}$. The investigation can also provide good guidance for the tool design and the process control.

\section{Experimental}

The experimental equipment is the self-designed device of semisolid rheo-rolling. The nominal diameter of the rolls is $400 \mathrm{~mm}$, and the rolling speed is $22 \mathrm{~m} / \mathrm{min}$. The cross section size of the strip is $4 \mathrm{~mm} \times 160 \mathrm{~mm}$. As shown in Fig. 1, the melt is poured onto the vibrating sloping plate surface. Then the melt nucleates rapidly under the strong cooling condition. Due to the vibration and melt flow, semisolid alloy with fine non-dendrites and remnant liquids can be obtained. The two broadsides of the roll gap are constrained by the convex and concave rolls, so there are four friction forces on the melt, as shown in Fig. 1. The semisolid slurry is rolled directly by the shape rolling mill. This process has two main advantages: (1) The semisolid alloy needs short solidification time, so the process is expected to be developed as a high-speed semisolid roll-casting technique; (2) The microstructure and the mechanical properties of the product are better than that produced by conventional roll casting. The main chemical compositions (wt.\%) of the experimental material AZ91 magnesium alloy are Al 9.0, Zn 1.0, Mn 0.2, $\mathrm{Cu}$ 0.05, Ni 0.01, Fe 0.01 and $\mathrm{Mg}$ balanced. The liquids and solidus temperatures of the alloy are $595{ }^{\circ} \mathrm{C}$ and $470{ }^{\circ} \mathrm{C}$, respectively. The alloy slurries about $5 \mathrm{~g}$ at different positions on the sloping plate were taken and then quenched in the water for microstructure observation, and the microstructure of the strip was observed. The microstructure observation was performed under an OLYMPUS PMG51 metallographic microscope. The SSX-550 scanning electron microscope (SEM) was also adopted to analyze the element distributions during the solidification the sloping plate.

\section{Results and Discussion}

\subsection{Microstructure formation mechanism of AZ91 magnesium alloy on the sloping plate surface}

The microstructures of the melt about $5 \mathrm{~g}$ taken and quenched in water at different positions on the sloping plate surface are shown in Fig. 2. When the casting temperature is $690{ }^{\circ} \mathrm{C}$, the primary grain on the sloping plate transformed into fine spherical or rosette grains gradually, and the grain size also decreased with the alloy flow from upper position A to the bottom position $\mathrm{D}$ (the corresponding positions are shown in Fig. 1). The average grain size decreases from 40 to $25 \mu \mathrm{m}$, which is shown in Fig. 3. The 

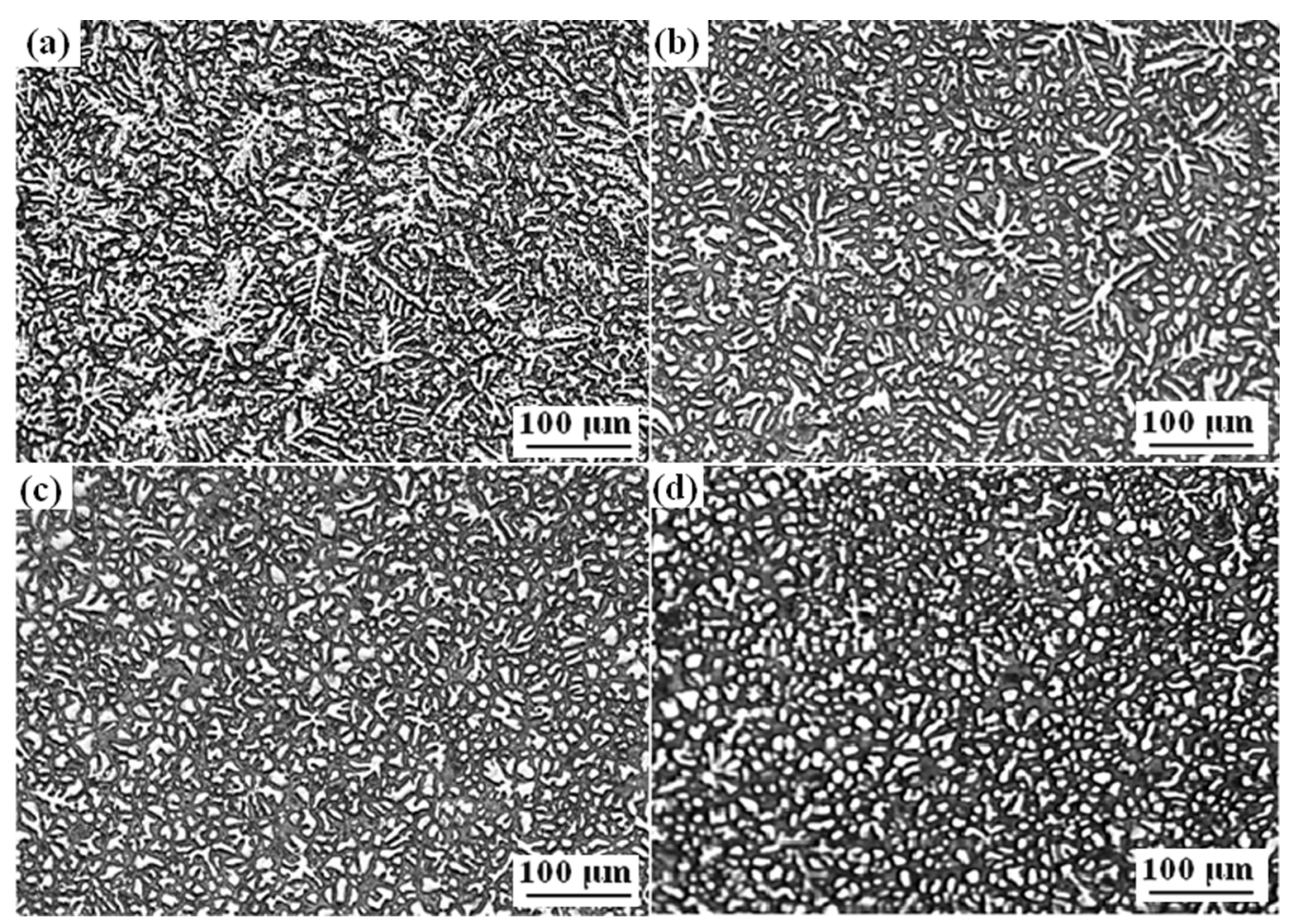

Fig. 2 Microstructures of the melt about $5 \mathrm{~g}$ quenched in water at different positions of the sloping plate when casting at $690{ }^{\circ} \mathrm{C}$, corresponding to positions A (a), B (b), C (c) and D (d) in Fig. 1

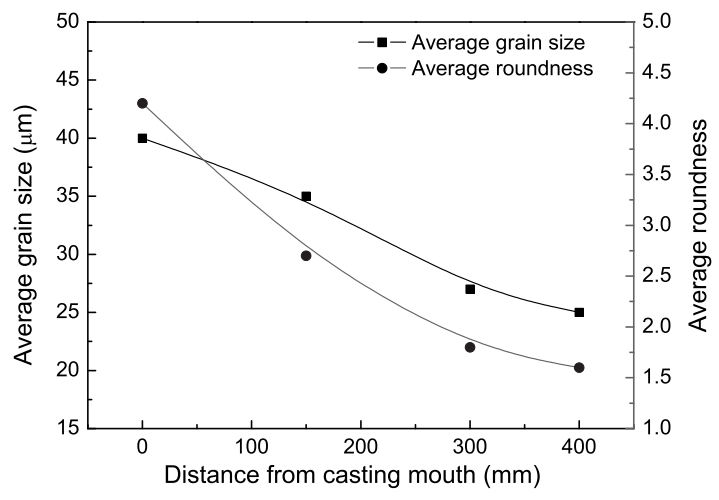

Fig. 3 Variations of the grain size and roundness during the flow process on the plate surface when the casting is $690{ }^{\circ} \mathrm{C}$

average roundness of the primary grains decreases from 4.2 to 1.6 which indicates that more and more nuclei generated during the flow process. At positions $\mathrm{A}$ and $\mathrm{B}$, there were little nuclei forming in the melt. So the primary grains grew into big dendrites after quenching. But at positions $\mathrm{C}$ and $\mathrm{D}$, a large number of nuclei formed in the melt, which led to the formation of fine primary grains in the quenched alloy.

It is widely accepted that the fine microstructure formation during the sloping plate process is due to the formation of a large number of heterogeneous nuclei on the cooling sloping plate. But there is no clear evidence. Actually, nucleus formation is related to two actions, the strong cooling ability of the sloping plate and the stirrings by metal flow and vibration. In order to analyze the microstructure formation mechanism, the features of the temperature and the flow velocity boundary layers during the process must be investigated firstly. As we all know, there exists metal flow velocity boundary layer $\delta$ near the plate surface and temperature boundary layer $\delta_{\mathrm{t}}$ during the process. The thicknesses of the two layers follow the relationship of

$$
\delta_{\mathrm{t}}=\frac{\delta}{\operatorname{Pr}^{1 / 3}}
$$

where $\operatorname{Pr}$ is the Prandtl number of the alloy. The $\operatorname{Pr}$ of liquid metal is about $0.004-0.029$, so the thickness of temperature boundary layer is much larger than that of the velocity boundary layer. There is only a tiny velocity boundary layer near the plate surface. While the temperature boundary layer is distributed almost in the entire alloy and is relatively homogenous. At the same time, the cooling plate can provides a strong cooling rate. It can be calculated by the convection heat transfer formula that the cooling rate of the melt on the plate surface is much larger than $100 \mathrm{~K} / \mathrm{s}$ for conventional casting process, which implies that the undercooling is easy to form in the most of the melt ${ }^{[22]}$. The melt flow and vibration can affect the diffusion coefficient and the solute distribution. From the entrance of the sloping plate to the exit of the sloping plate, the flow velocity gradually increase, which causes the homogeneous solute distribution, in addition, vibration accelerates stirring of the melt and is helpful to establish homoge- 


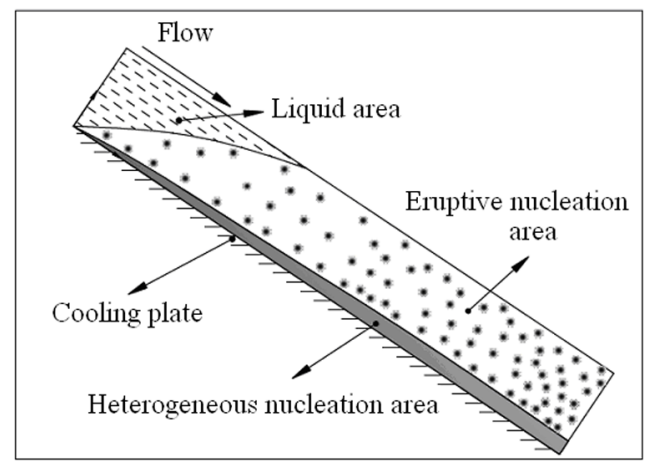

Fig. 4 Schematic diagram of the nucleation mechanism

nous solute and temperature fields, so the homogeneous solute distribution can be formed. At the same time, the temperature boundary layer is distributed almost in the entire alloy and is relatively homogenous. In this case, when the critical condition for nucleation is satisfied, the uniform solute and temperature distributions can induce eruptive nucleation, and the melt is rapidly cooled by the plate, the eruptive nucleation happens in the most of the melt on the plate surface, as shown in Fig. 4. The microstructures of the melt quenched directly in water and the longitudinal section of the melt quenched on the plate surface are shown in Fig. 5, when the casting temperature is $690{ }^{\circ} \mathrm{C}$. Obviously, when the melt was quenched directly in the water, few nuclei formed, and the dendrites ripened completely. On the contrary, there is no obvious dendrite in the solidified alloy on the plate, which indicates that the cooling plate can provide a big cooling rate that is much faster than that of the water quenching. So once the melt is cast onto the cooling plate, a large number of nuclei will form and lead to fine microstructure formation ${ }^{[20-23]}$.

As shown in Fig. 4, besides the eruptive nucleation, there are always large heterogeneous nuclei forming on the plate surface. Generally, the nuclei adhere on the plate surface under static condition and extend further until they contact with each other, and a solidification shell forms eventually. But under the flow and the vibration, the nuclei forming on the plate surface can disperse into the whole melt. So the quantity of the effective nucleus is greatly improved, and fine and spherical grain forms.

During the primary grain growing process, dendrite breakage also takes place. Perhaps, the stirring caused by the vibration and metal flow cannot lead a perfect dendrite to break. However, since AZ91 alloy contains high-level element of $\mathrm{Al}$, which decelerates the solidification rate of the dendritic arm root. So these areas may neck down under heat flux and the stirring easily. Dendritic arm fragments can grow further and evolve into fine spherical grains ${ }^{[20,24]}$. Fig. 6 shows the microstructure and element distributions of the quenched melt taken from position $\mathrm{B}$ on the sloping plate. After etched by the acid, positions 1 , 2, 3 and 4 in Fig. 6 show the segregations of the elements. Many grain boundaries were divided by etching, which also implies that these arms are weak and could be easily broken up under the actions of heat flux, the vibration and metal flow. So the vibrating amplitude can greatly affect the microstructures of the alloys.

Fig. 7 shows the microstructures of the quenched slurry prepared by the vibrating sloping plate process under different vibrating amplitudes of $0.5 \mathrm{~mm}$ and $1.5 \mathrm{~mm}$. As shown in Fig. 7, at a certain scope, microstructure becomes finer and rounder with the increment of the vibrating amplitude. Larger amplitude can cause stronger vibration and lead more dendritic debris to form, and finer microstructure can be obtained. But the amplitude should not exceed $1.6 \mathrm{~mm}$, because the slurry will splash off the plate when the amplitude is over $1.6 \mathrm{~mm}$. Besides dendritic growth and dendrite breakage, the direct globular growth of grains happens. Ref. [20] mainly reported on the mechanism of the dendrite fracture, and did not intensively study the mechanism of the direct globu-

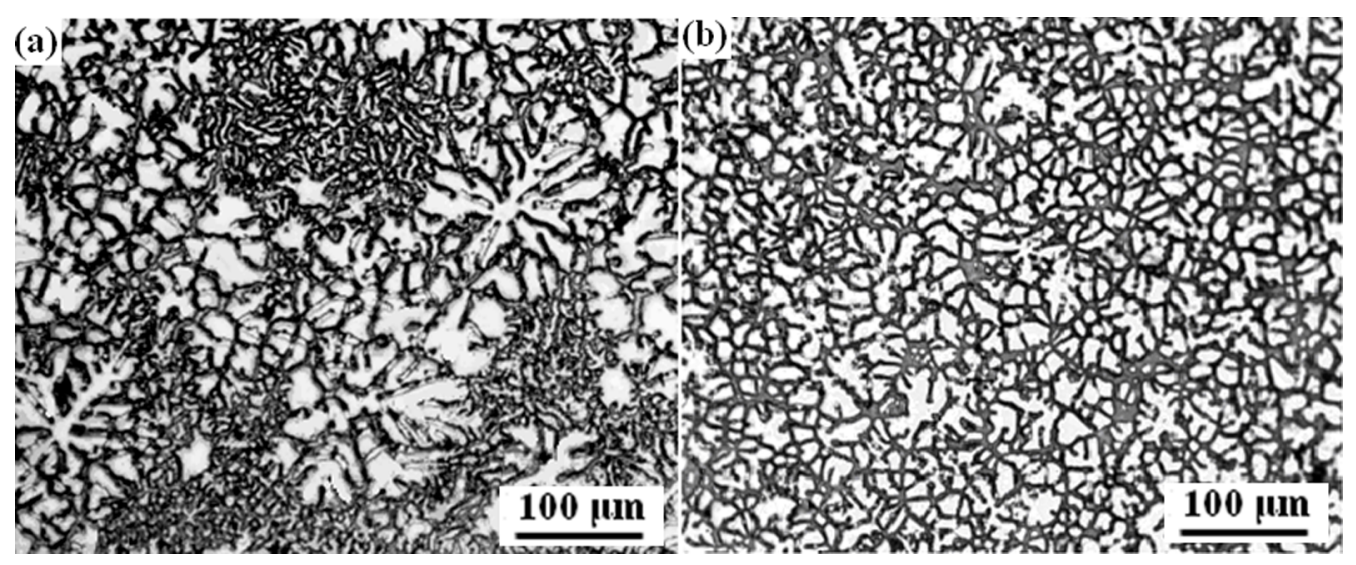

Fig. 5 Comparison of the microstructures of direct quenched melt and the solidified alloy on the plate surface: (a) direct water quenching; (b) solidification on the stationary plate surface without flow 

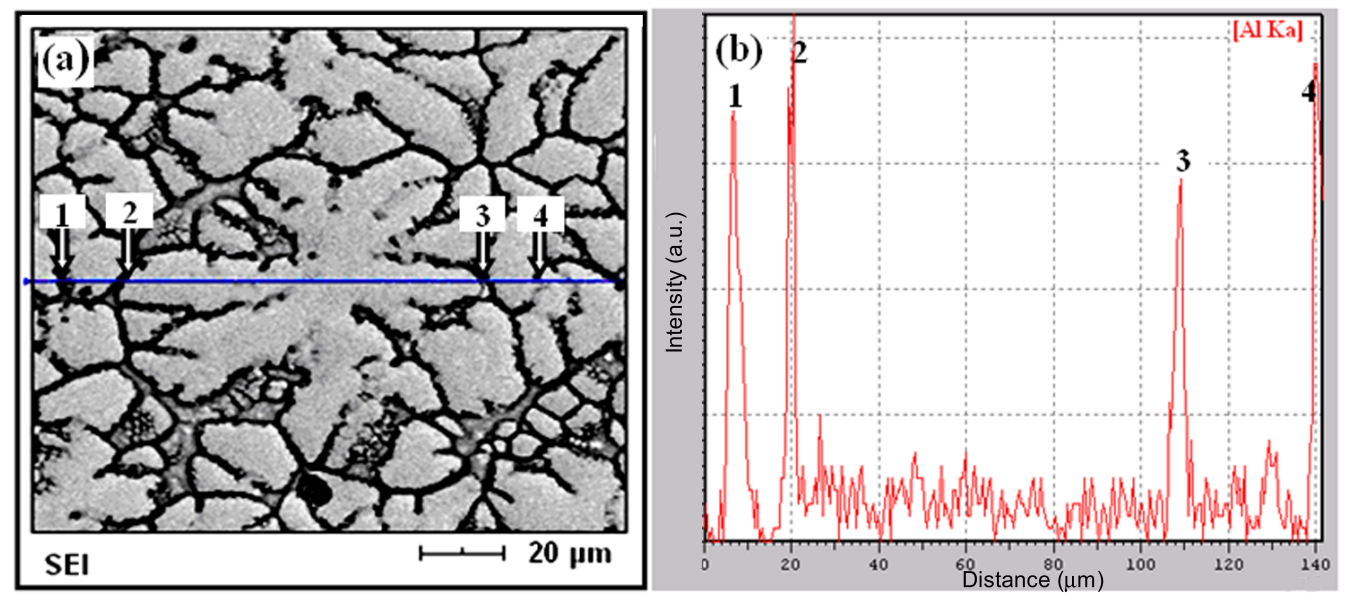

Fig. 6 SEM micrograph (a) and Al element distribution along the line in Fig. 6(a) (b) of the quenched melt taken from the position $\mathrm{B}$ on the plate

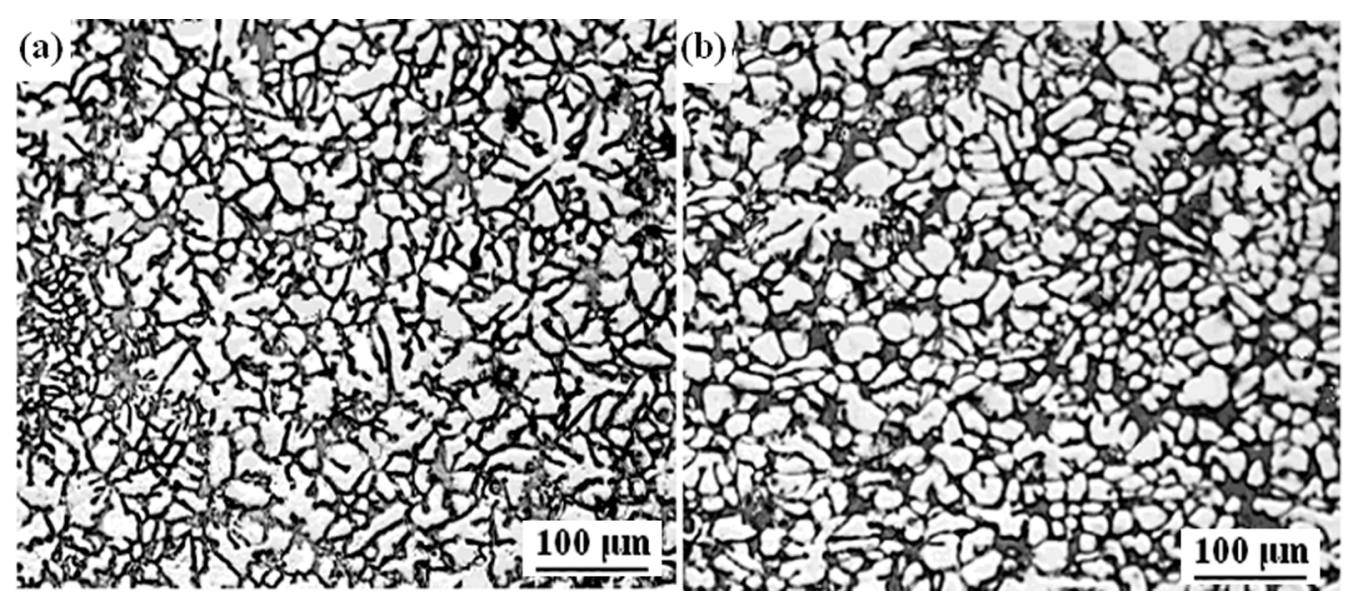

Fig. 7 Microstructures of the quenched slurry prepared by the vibrating sloping plate process under different vibrating amplitudes of $0.5 \mathrm{~mm}$ (a) and $1.5 \mathrm{~mm}$ (b)

lar growth of grains. The mechanism of the direct globular growth of grains was studied in this work. During the grain growth process, the stable state of grain surface is very important for the style of the grain growth. The surface stability mainly depends on the concentration gradient of the constituent and the real temperature gradient. During the vibrating sloping plate process, strong stirring induced by the vibration and metal flow can lead to a big diffusion coefficient of the constituent, and then it can cause a small concentration gradient of the constituent, which is favorable for decreasing destabilization frequency, so the grain surface can keep a stable state and grow with a spherical pattern.

The effective nucleation rate determines the final grain size and microstructure. So it is very important to improve the effective nucleation rate as high as possible. The effective nucleation rate is affected by the casting temperature, while Ref. [20] did not reported on the effects of casting temperature on the microstructure of the product during the rheo-rolling process. In order to guide the rheo-rolling process, this work studied the effects of casting temperature on the microstructure of AZ91 strip, and optimized process parameters. The effective nucleus decreases and the grain size increases with the increment of the casting temperature. So the casting temperature should be kept at a low level. However, the cast ability of the alloy should also be considered. Because the flow ability and cast ability of the alloy become worse when the solid fraction is too high at low temperature, the casting temperature should not be too low. When the casting temperature was lower than $650{ }^{\circ} \mathrm{C}$, the flow ability of the melt was very poor, and the process also failed. If the casting is higher than $730{ }^{\circ} \mathrm{C}$, the semisolid zone of AZ91 alloy on the sloping plate is very little, which is not favorable for preparing semisolid slabs, the casting temperature should be set lower than $730{ }^{\circ} \mathrm{C}$. So the casting temperatures were varied from 650 to $730{ }^{\circ} \mathrm{C}$.

\subsection{Microstructure formation mechanism of AZ91 magnesium alloy in the roll gap}

Fig. 8 shows the microstructures of the strips 


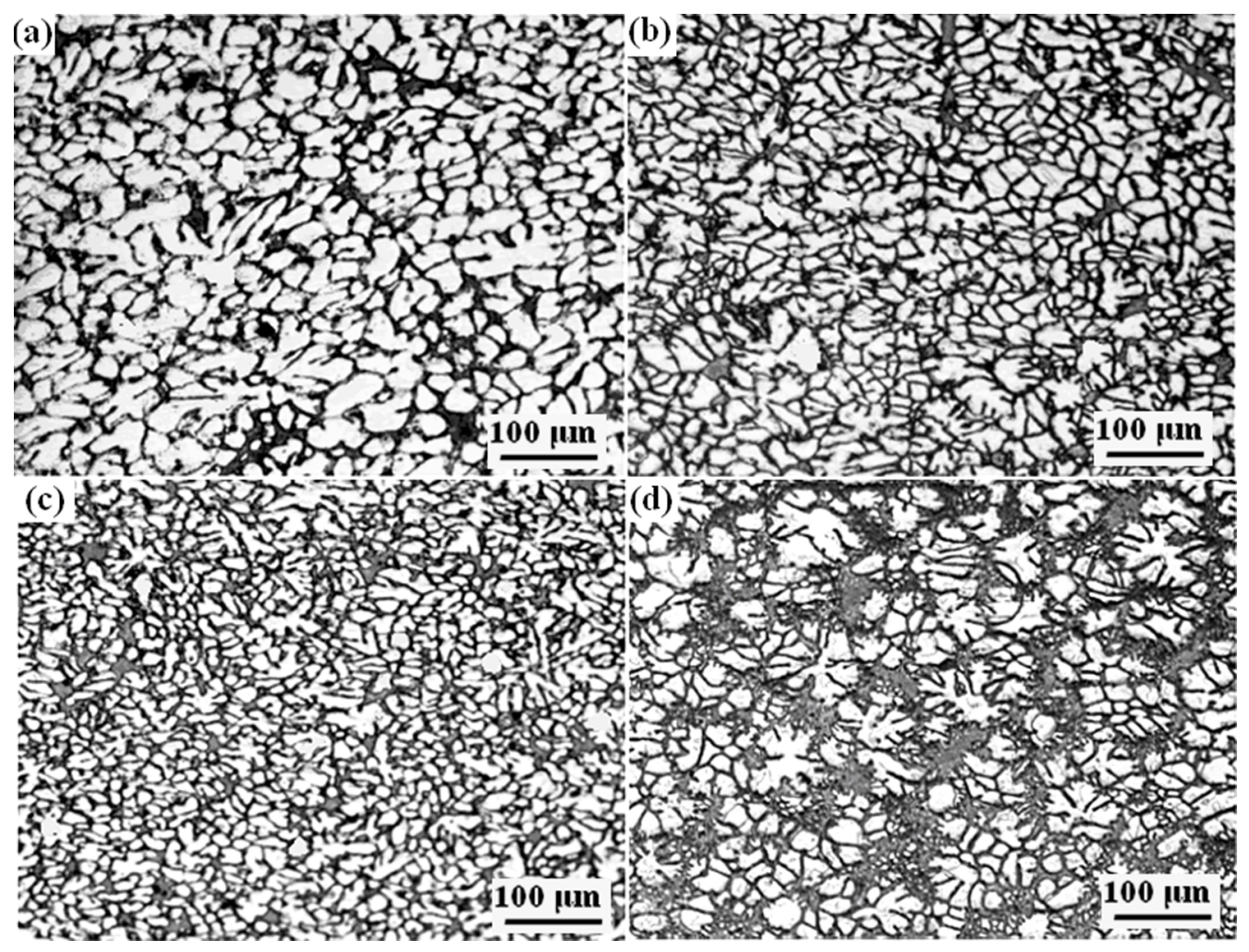

Fig. 8 Microstructures of the strips along the rolling direction at different casting temperatures of $650{ }^{\circ} \mathrm{C}(\mathrm{a})$, $670{ }^{\circ} \mathrm{C}(\mathrm{b}), 690{ }^{\circ} \mathrm{C}(\mathrm{c})$ and $710{ }^{\circ} \mathrm{C}(\mathrm{d})$

along the rolling direction at different casting temperatures. From Fig. 8, it is found that the plastic deformation almost did not happen in the strip of AZ91 magnesium alloy. The microstructures of the strips under different casting temperatures are mainly composed of fine spherical or rosette grains. Comparing Fig. 2 and Fig. 8, it can be found that the primary grains grew further in the roll gap. The experimental results also show that the microstructure of the strip varied with the casting temperature. It can be concluded that the primary grain growth mainly took place in the roll gap. The primary grain growth during flow process on the plate was not obvious. In addition, under strong cooling condition provided by the water-cooling rolls, the secondary crystallization of the remnant liquids occurred in the roll gap. So during this period, the liquid phase transformation is key factor that influences the final microstructure of the strip. In the casting temperature range from 650 to $690{ }^{\circ} \mathrm{C}$, the whole remnant liquids in the roll gap can obtain enough undercooling and reach the nucleation condition, so it is favorable to the formation of spherical or rosette grains. The more the remnant liquids are, the more spherical or rosette grains form. So the average grain size decreases with the increment of the casting temperature when that casting temperature is between 650 and $690{ }^{\circ} \mathrm{C}$, as shown in Fig. 9. However, when the casting temperature reached $710{ }^{\circ} \mathrm{C}$, due to the high temperature, little primary nuclei formed on the plate, simultaneously,

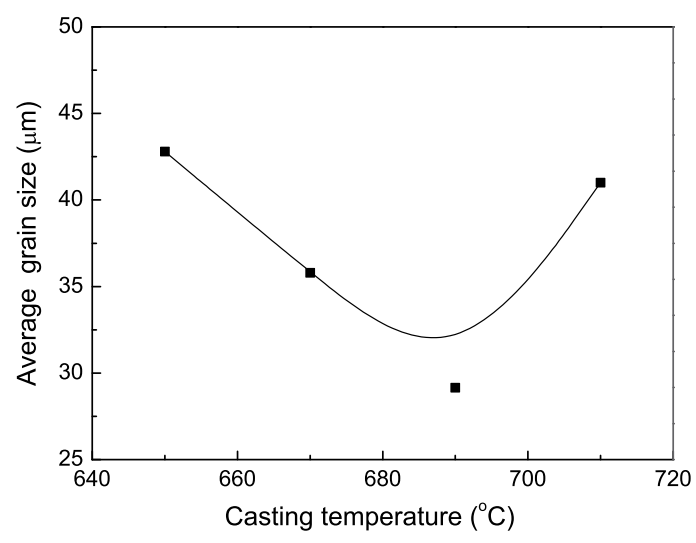

Fig. 9 Effect of the casting temperature on the grain size

there was also little nucleus formed in the roll gap. In this case, a part of the liquid alloy transformed into the eutectic phase, and the primary grains ripened to coarse dendrites, as show in Fig. 8d. So the casting temperature should be controlled in the range from 650 to $690{ }^{\circ} \mathrm{C}$.

\subsection{Microstructure of the AZ91 alloy strip produced by the proposed process}

The experimental results show that when the casting temperature was from 650 to $690{ }^{\circ} \mathrm{C}$, the AZ91 alloy strip could be successfully produced by the present process. The microstructure of the strip manufactured at the casting temperature of $690{ }^{\circ} \mathrm{C}$ mainly 
(a)
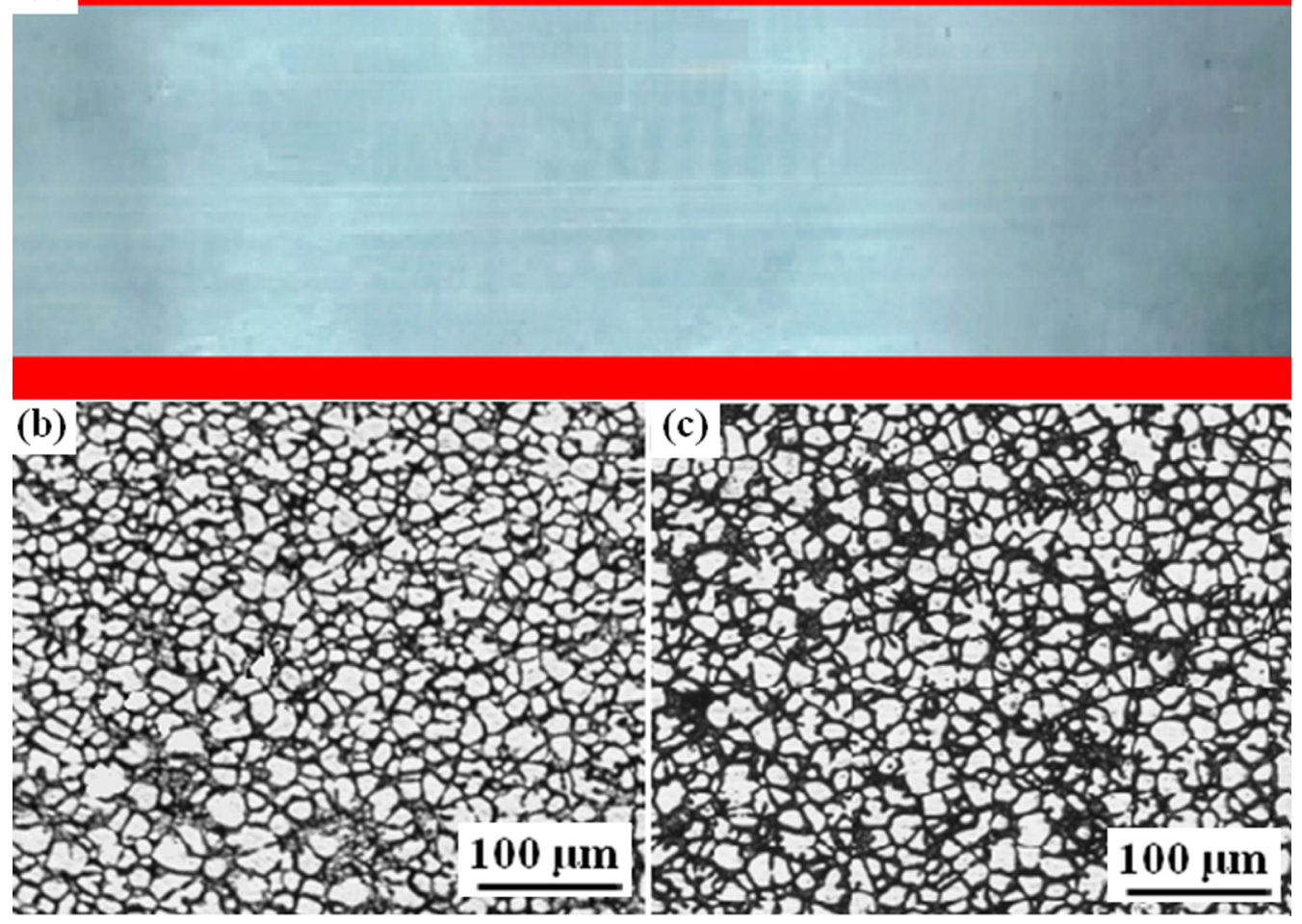

Fig. 10 Macrophotograph and microstructures of AZ91 alloy strip obtained at the casting temperature of $690{ }^{\circ} \mathrm{C}$ : (a) macrophotograph; (b) microstructure of the product on the longitudinal section; (c) microstructure of the product on the cross section

composed of fine spherical or rosette grains, as shown in Fig. 10.

\section{Conclusions}

In this paper, a novel semisolid rheo-rolling process of AZ91 alloy was proposed. In the casting temperature range from 650 to $690{ }^{\circ} \mathrm{C}$, AZ91 alloy strip with fine spherical or rosette grains was prepared by the proposed process. During the grain growth process, the grain breakage took place and transformed into fine spherical or rosette grains on the sloping plate gradually, the other grain growth style is direct globular growth. Due to the secondary crystallization of the remnant liquids in the roll gap, the microstructure of the strip becomes finer with the increment of the casting temperature from 650 to $690{ }^{\circ} \mathrm{C}$. But when the casting temperature reached $710{ }^{\circ} \mathrm{C}$, a part of the liquid alloy transformed into the eutectic phases, and the primary grains ripened to form coarse dendrites.

\section{Acknowledgements}

This work was financially supported by the National Natural Science Foundation for Outstanding Young Scholars of China (No. 51222405), National Natural Science Foundation of China (No. 51034002), the Fok Ying Tong Education Foundation (No. 132002), the Basic Sci- entific Research Operation of Center University (Nos. N120602002 and N120502001) and Chinese National Program for Fundamental Research and Development (No. 2011CB610405).

\section{REFERENCES}

[1] J.F. Jiang, Y. Wang and S.J. Luo, Mater. Charact. 58 (2007) 190.

[2] M. Celikin, F. Zarandi, D. Sediako and M.O. Pekguleryuz, Can Metall. Q. 48 (2009) 419.

[3] A. Sadeghi and M. Pekguleryuz, Mater. Charact. 62 (2011) 742.

[4] L.J. Hu, Y.H. Peng, Y.D. Li and S.R. Zhang, Mater. Manuf. Process. 25 (2010) 880.

[5] N. Giguère, S. Amira, R. Tremblay, C.A. Loong and D. Dubé, Can Metall. Q. 47 (2008) 163.

[6] L. Vuong, L. Jiang, J.J. Jonas, S. Godet, B. Verlinden and P. Van Houtte, Can Metall. Q. 47 (2008) 437.

[7] M.C. Flemings, Metall. Trans. A 22 (1991) 957.

[8] Z. Liu, Y.M. Hu and X.M. Liu, Acta Metall. Sin. (Engl. Lett.) 23 (2010) 277.

[9] S. Ji, Z. Fan and M.J. Bevis, Mater. Sci. Eng. A 299 (2001) 210

[10] H. Mehrara, M. Nili-Ahmadabadi, B. Heidarian, S. Ashouri and J. Ghiasinejad, Solid State Phenom. 141-143 (2008) 785.

[11] R.G. Guan, Z.H. Xing, L. Shi, C. Wang and Y. Wang, Mater. Sci. Forum 561-565 (2007) 865.

[12] T. Motegi, Int. J. Mater. Prod. Technol. 2 (2001) 468. 
[13] P. Kapranos, T. Haga, E. Bertoli and A. Pola, Z. Azpilgain and I. Hurtado, Solid State Phenom. 141143 (2008) 115.

[14] T. Grimmig, A. Ovcharov, C. Afrath, M. Bunck and A. Buhrig-Polaczek, Solid State Phenom. 116-117 (2006) 484.

[15] P. Babaghorbani, S. Salarfar and M. Nili-Ahmadabadi, Solid State Phenom. 116-117 (2006) 205.

[16] T. Haga, J. Mater. Process. Technol. 130-131 (2002) 558.

[17] T. Haga, M. Saito, S. Kumai and H. Watari, Adv. Mater. Res. 97-101 (2009) 1057.

[18] R.G. Guan, Z.Y. Zhao, C. Lian, T. Cui and C.S. Lee, Met. Mater. Int. 19 (2013) 33.
[19] R.G. Guan, Z.Y. Zhao, X.P. Sun, H.Q. Huang, C.G. Dai and Q.S. Zhang, Trans. Nonferrous Met. Soc. China 20 (2010) 729.

[20] R.G. Guan, Z.Y. Zhao, H. Zhang, C. Lian and C.S. Lee, J. Mater. Process. Technol. 212 (2012) 1430.

[21] R.G. Guan, Z.Y. Zhao, R.Z. Chao, Z.X. Feng and C.M. Liu, Trans. Nonferrous Met. Soc. China 22 (2012) 2871.

[22] S.M. Yang, Fundamentals of Heat Transfer, Higher Education Press, Beijing, 2003, p.140. (in Chinese)

[23] R.G. Guan, F.R. Cao, L.Q. Chen, J.P. Li and C. Wang, J. Mater. Process. Technol. 209 (2009) 2592.

[24] R.G. Guan, C. Wang, Z.H. Xing, C.S. Lee and F.Y. Hu, Mater. Sci. Technol. 23 (2007) 438. 